\title{
Evaluation of The Effect of Gardening Intervention on nutritious foods Consumption of Children and Adolescent: A Systematic Review
}

\author{
Ayudiah Uprianingsih \\ Faculty of Nursing, Universitas Airlangga \\ Surabaya, Indonesia \\ Ayudiah.uprianingsih-2016@fkp.unair.ac.id \\ Winda Agustina \\ Faculty of Nursing, Universitas Airlangga \\ Surabaya, Indonesia
}

\author{
Uchira Uchira \\ Faculty of Nursing, Universitas Airlangga \\ Surabaya, Indonesia \\ uchira-2016@fkp.unair.ac.id
}

\begin{abstract}
Gardening Intervention is one of the interventions that have been widely used to increase the intake of nutrition in children and adolescents. We identified articles through databases searching: Sage, Proquest, Science Direct, Springerlink, and EbscoHost, published between (2006-2016). The fifteen articles were analyzed and selected from 1473: The studied evaluated that the gardening intervention are recommended for the children and adolescents to increase their nutrition intake in home, school and community setting. However, many of these studied still lacked of intervention length, method and sample size So we suggest to do further research by using more $\mathrm{RCT}$, with good preparation in all aspect,to succeed the implementation and application of the program.
\end{abstract}

Keywords-component; Gardening, Nutrition, Children, adolescent

\section{INTRODUCTION}

Good nutrition during the early period of life is a crucial requirement for optimal growth and development to determine the quality of life in the future [1]. Lifestyle or behavior that is learned early will provide short term impacts and long term impact for the children [2].

World Health Organization estimates that less consumption of nutritious foods such as fruit and vegetables contributed to 2.7 million deaths caused by chronic diseases [3]. The epidemiological survey conducted in Australia showed a lack of fruit and vegetable consumption was identified as one of the top ten Global causes of death risk factors [4] Various studies showed results that less fruit and vegetable consumption can increase the risk of degenerative diseases in later life, such as hypertension, diabetes, cardiovascular disease, and cancer [5].

In Indonesia data are available that fruit and vegetable consumption in the society is still relatively low, based on the results of basic health research. Riskesdas (2013) showed that fruit consumption in some provinces in
Indonesia is still very low, and there is no significant increase from previous data in 2007 [6]. Some of the provinces are South Kalimantan, West Kalimantan, Central Kalimantan, Central Sulawesi, West Sulawesi, South Sulawesi, Southeast Sulawesi, North Sulawesi, Gorontalo, Jakarta, East Java, West Nusa Tenggara, Jambi, and Bengkulu [6].These data suggest that the problem of low fruit and vegetable consumption occurs in almost all regions of Indonesia.

A variety of interventions have been made to increase the knowledge of nutritious food consumption in children, one of the intervention that has been used is Gardening Intervention or gardening Activities applied in the school environment, in the family environment and in the community setting. Gardening based nutrition The intervention was rated as one of the effective ways to increase nutritious food consumption in children and adolescents.

\section{METHODS}

We identified articles through databases searching: Sage, Proquest, Science Direct, Springerlink, and EbscoHost, published between (2006-2016), search terms include various combination of the terms "Gardening", "nutrition", "Children", and "Adolescent". We found fifteen articles that suitable with our Inclusion Criteria. Our inclusion criteria are all kind of gardening intervention in the form of any kind of gardening programs ranging from education about the benefits of gardening and also gardening activity, either at home, school or community that given an impact on knowledge of food consumption on children ages 2-15 years. All articles using the English language were included. We excluded the articles if the target population focused on adults, elderly or society. 


\section{RESULTS}

Fifteen articles that have been collected, analyzed and scored, obtained the following results. Research conducted by Hutchinson (2015) aimed to compare the effectiveness of interventions provided by Royal gardening holticultural and by the teacher to know the knowledge about healthy nutrition and also the level of fruit and vegetable consumption on the results obtained that gardening Interventions guided by the teacher showed the higher level of vegetable and fruit consumption than the intervention that is guided by the RHS $(p=0,009)$ [7]. In the meantime research conducted by Brouwer and Nelson (2013) was to compare the level of intake of the nutrients in the intervention group and the control group, the results of the research show that the level of vegetable intake improved in the intervention group compared with the control group, but no significant difference of the statistical results was found [8].

Research conducted by Evans et al (2016) aimed to know the influence of gardening interventions and physical activity on the prevalence of a healthy diet, physical activity, and weight status in school aged children [9]. The research results showed that the preferences of vegetable consumption were higher in the intervention group compared to the comparison group (8.7 Vs. 8.3), but in general showed no significant differences between the intervention group and comparison group.

The study by Christian et al (2014) aims to evaluate whether school gardening program guided by a teacher or RHS give an effect on vegetable and fruit intake in children or not [10]. The result showed there were no significant differences in the intake of vegetables and fruit in the intervention group and the control group. Research conducted by Gibbss et al (2013), aimed to evaluate the results of gardening intervention and cooking program with Stephanie alexander on the consumption of a healthy diet of age school children, the results of the study showed the levels of consumption of vegetables and fruit in the intervention group was higher than the control group. From a quantitative test results showed an increase in the desire of children to try new food $(\mathrm{p}=0.001)$ [11].

Research by Parmer et al (2009) aimed to find out the influence of intervention in schools gardening against the level of knowledge, the selection of the preferred types and levels of fruit and vegetable consumption in children in primary schools the results of the study showed the levels of consumption of vegetables and fruit in the intervention group was higher compared to the control group [12]. Participants in the intervention group $\mathrm{NE}+\mathrm{G}$ (nutrition and gardening Education) has a vegetable and fruit consumption levels higher compared to the control group $(\mathrm{P}=0.01)$.

The research by Heim (2009) aimed to find out the influence of summer camp gardening on fruit and vegetable intake in children of school age [13]. Most of the children $(97.8 \%)$ liked to try snack of vegetables, gardening activity (93.4\%), and activity like gardening. Data showed a significant increase in the demand for children on fruit and vegetable consumption at home ( $\mathrm{p}<0002)$. Research by Triador Lucila et al (2014) aims to evaluate the benefits of a seven month program intervention, research results improved significantly to the selection and consumption of vegetables and fruit or a combination of both $(\mathrm{p}<0.017)$.

Research by Castro et al (2013) aimed to evaluate the influence of the program "Growing Healthy Kids" in the community and home setting, and to prevent of obesity in children, by increasing healthy eating habits (fruits and vegetables). The data showed an increase in vegetable and fruit consumption in children with families who get the treatment gardening intervention $(\mathrm{p}=0.001)$ [14].

Research of Jaenke (2012) aims to know the difference effects on gardening program between boys and girls on the intake of vegetables, the desire to eat vegetables and fruit, and also the level of consumption of fruit and vegetables [15]. Results of the study showed higher carrot consumption in children of women $(\mathrm{p}=0.004)$, there is no significant difference between boys and girls on the item of desire to try vegetable, but there is an effect group that both men and women have a high desire to consume vegetable. $(\mathrm{p}<0.001)$.

Research conducted by Ractcliffe (2011) aims to know influence of gardening education intervention on children's knowledge about healthy nutrition, and fruit and vegetable consumption. The results of the study showed the intervention group consume more fruit and vegetables than the control group $(\mathrm{p}=0.01)$ [5].

The research of Mc Aleesee et al (2007) aims to find out the effect of gardening education intervention on fruit and vegetable consumption in aged school children, the results showed an increase in the consumption of fruit, with the significant result showed after intervention i.e.: 1.13 servings per day, $(\mathrm{p}=0.001)$, vegetable $=1.44$ servings per day $(\mathrm{P}=$ $0.001)$. Research from smith and lauren Lautenschlager chery (2007) aims to find out whether the intervention of gardening can transform healthy eating habits in teenagers who live in the urban city. Results showed that vegetable and fruit Consumption increased in boys but did not increase in girls $(\mathrm{p}<0.01)$

\section{DISCUSSION}

The studies examined in this Systematic Review were about the gardening intervention that is associated with the child's knowledge about healthy nutrition and the habits of consuming vegetables and fruit, the settings of the selected environment are at school, at home and in the community, the third element is very closely related to each other and should synergize supports the needs of nutrition in children. The problem of lack of consumption of nutritious food in children and adolescents need to get special attention. In this case the role of the nurse is indispensable Particularly the role of community health nurse. Community nurse has role in primary, secondary and tertiary prevention in helping communities or families to identify the needs of the family that related to consumption of fruit and vegetables [16]. At the level of primary care nurse can implement health education intervention, one of them is to do gardening intervention, the nurse should certainly also collaborate with various element, such as parents, teachers, community 
leaders and etc. At the level of secondary prevention nurses can do the screening in children and adolescents who consume less fruit and vegetables. At the tertiary level nurse can be instrumental in reducing the potential negative impact of the lack of consuming fruit and vegetable [17].

\section{CONCLUSIONS}

This study evaluated the effect of gardening intervention on nutritious food intake, a healthy diet, of children and adolescent. The 15 studies reviewed, 10 indicated that a gardening intervention influenced knowledge about nutrition, healthy eating patterns, and changes in attitude of children in choosing and consuming nutritious food. The five other studies showed an increase in the consumption of fruit and vegetables but not supported by statistical data. Fifteen article shows diversity, ranging from the duration of the study participant, place, age, sex, economic status and etc. It also showed different effects on the results of the research.

Majority of fifteen studies showed significant positive effects on vegetable and fruit consumption in children in schools. The journals research conducted by Brouwer Naemenek (2013), showed that increased consumption of vegetables and fruit occur in the school environment, whereas no significant change occurred against the consumption of fruit and vegetables at home. Future expected, roles of the parents should be more involved. In addition, some of the research also showed that a combination of nutrition education, with gardening intervention more effective in increasing knowledge about healthy food intake in children as well as fruit and vegetable consumption, therefore also are expected in the next research, education regarding nutrition combined with gardening intervention need to be developed more. In addition the validity and reliability measuring instrument must also be improved. RCT studies also should continue to be done to find out the actual effect and to avoid bias in research.

\section{REFERENCES}

[1] R. . et al. Pabayo, "Food Consumption in Preschooler children," Can. J. Diet. Pract. Res., vol. 73, no. 2, 2012.

[2] M. R. Friedman, V. R. Bowden, and E. Jones, Family Nursing: Research, Theory, and Practice, 4th ed. Philadhelphia: Lipincot williams \& Wilkins, 2010

[3] Kemenkes RI, Pedoman Gizi Seimbang. Jakarta: Kementrian Kesehatan RI, 2014
[4] et al. Martinez, L. C., "Design and methodology of the LA Sprouts nutrition, cooking and gardening program for Latino youth: A randomized controlled intervention," Contemp. Clin. Trials, vol. 42, pp. 219-227, 2015.

[5] M. M. Ratcliffe, K. A. Merrigan, B. L. Rogers, and J. P. Goldberg, "The Effects of School Garden Experiences on Middle School-Aged Students' Knowledge, Attitudes, and Behaviors Associated With Vegetable Consumption," Health Promot. Pract., vol. 12, no. 1, pp. 36-43, 2011.

[6] Badan Penelitian dan Pengembangan Kesehatan, Riset Kesehatan Dasar (RISKESDAS) 2013. 2013.

[7] J. Hutchinson, M. S. Christian, C. E. L. Evans, C. Nykjaer, N. Hancock, and J. E. Cade, "Evaluation of the impact of school gardening interventions on children's knowledge of and attitudes towards fruit and vegetables: a cluster randomised controlled trial," Appetite, vol. 91, pp. 405-414, 2015.

[8] R. J. . Brouwer and S. E. B. Neelon, "Watch Me Grow: A gardenbased pilot intervention to increase vegetable and fruit intake in preschoolers," BMC Public Health, vol. 13, no. 363, 2013.

[9] A. Evans, N. Ranjit, C. N. Fair, R. Jennings, and J. L. Warren, "Previous Gardening Experience and Gardening Enjoyment Is Related to Vegetable Preferences and Consumption Among LowIncome Elementary School Children,” J. Nutr. Educ. Behav., vol. 48, no. 9, p. 618-624.e1, 2016.

[10] M. S. Christian, C. EL Evans, C. Nykjaer, N. Hancock, and J. E. Cade, "Evaluation of the impact of a school gardening intervention on children's fruit and vegetable intake: a randomised controlled trial," Int. J. Behav. Nutr. Phys. Act., vol. 11, no. 99, 2014.

[11] L. Gibbs et al., "Expanding Children's Food Experiences: The Impact of a School-Based Kitchen Garden Program,” J. Nutr. Educ. Behav., vol. 45, no. 2, pp. 137-146, 2013.

[12] S. M. Parmer, J. Salisbury-Glennon, D. Shannon, and B. Struempler, "School Gardens: An Experiential Learning Approach for a Nutrition Education Program to Increase Fruit and Vegetable Knowledge, Preference, and Consumption among Second-grade Students," J. Nutr. Educ. Behav., vol. 41, no. 3, pp. 212-217, 2009.

[13] S. Heim, J. Stang, and M. Ireland, "Perspectives in Practice A Garden Pilot Project Enhances Fruit and," YJADA, vol. 109, no. 7, pp. 1220 1226, 2009.

[14] D. C. Castro, M. Samuels, and A. E. Harman, "Growing Healthy Kids: A community garden-based obesity prevention program," Am. J. Prev. Med., vol. 44, no. 3 SUPPL. 3, pp. S193-S199, 2013.

[15] R. L. Jaenke, C. E. Collins, P. J. Morgan, D. R. Lubans, K. L. Saunders, and J. M. Warren, "The Impact of a School Garden and Cooking Program on Boys' and Girls' Fruit and Vegetable Preferences, Taste Rating, and Intake," Heal. Educ. Behav., vol. 39, no. 2, pp. 131-141, 2012.

[16] S. V. Sharma, A. M. Hedberg, K. A. Skala, R.-J. Chuang, and T. Lewis, "Feasibility and acceptability of a gardening-based nutrition education program in preschoolers from low-income, minority populations," J. Early Child. Res., vol. 13, no. 1, pp. 93-110, 2015.

[17] D. Tamiru, A. Argaw, M. Gerbaba, A. Nigussie, G. Ayana, and T. Belachew, "Improving dietary diversity of school adolescents through school based nutrition education and home gardening in Jimma Zone: Quasi-experimental design," Eat. Behav., vol. 23, no. October, pp. 180-186, 2016. 